\title{
Evaluating the Levels of Nesfatin-1 and Ghrelin Hormones in Patients with Moderate and Severe Major Depressive Disorders
}

\author{
Sermin Algul ${ }^{1}$ and Oguz Ozcelik ${ }^{2}$ \\ ${ }^{1}$ Department of Physiology, Faculty of Medicine, Yuzuncu Yil University, Van, Turkey \\ ${ }^{2}$ Department of Physiology, Faculty of Medicine, Firat University, Elazig, Turkey
}

Objective The goal of this study was to evaluate the importance of nesfatin-1, acylated and des-acylated ghrelin, which are known as energy regulatory hormones, in patients with moderate and severe major depression disorders (MDD).

Methods Thirty patients with a moderate degree of MDD and, 30 with a severe degree of MDD were used as participants in this study. Thirty subjects without depression were enrolled as a control group. The Hamilton Depression Rating Scale was used to classify the patients with MDD. Blood samples were taken after overnight fasting. The plasma nesfatin-1, acylated ghrelin and des-acylated ghrelin levels were measured using a commercially available enzyme-linked immunosorbent assay kit.

Results The nesfatin-1, the acylated ghrelin and the des-acylated ghrelin levels were found to be significantly higher in severe MDD $(3.92 \pm 0.4 \mathrm{ng} / \mathrm{mL} ; 88.56 \pm 4.1 \mathrm{pg} / \mathrm{mL} ; 962.76 \pm 67 \mathrm{pg} / \mathrm{mL})$ as compared to moderate MDD $(2.91 \pm 0.5 \mathrm{ng} / \mathrm{mL} ; 77.63 \pm 4.19 \mathrm{pg} / \mathrm{mL} ; 631.16 \pm$ $35 \mathrm{pg} / \mathrm{mL})$, or the control $(1.01 \pm 0.3 \mathrm{ng} / \mathrm{mL} ; 58.60 \pm 9.00 \mathrm{pg} / \mathrm{mL} ; 543.13 \pm 62 \mathrm{pg} / \mathrm{mL})$, respectively.

Conclusion Although nesfatin-1 and ghrelin are known as adversely affecting the hormones involving the regulation of appetite and food intake, they all increase in depressive patients and are even associated with the severity of the disease. In clinical medicine, the evaluation of the role of nesfatin-1 and ghrelin in endocrine and neu-roendocrine regulation of major metabolic functions is an important key mechanism in solving numerous diseases associated with endocrine and neuroendocrine disturbance. Increased levels of nesfatin-1 and ghrelin may also be important criteria in describing the prognoses of the patients and the effectiveness of the treatments.

Psychiatry Investig 2018;15(2):214-218

Key Words Nesfatin-1, Acylated ghrelin, Des-acylated ghrelin, Major depression disorders.

\section{INTRODUCTION}

Major depressive disorder (MDD) is a serious psychiatric disturbance characterized by impaired mood and reduced interest or pleasure in daily activities, it is accompanied by weight change, sleep disturbance, fatigue and reduced physical capacity. The pathogenesis of MDD has been shown to be related to hypothalamic-pituitary-adrenal axis dysfunction, immune system abnormality and important alteration in monoamine receptor activities especially the lack of serotonin. ${ }^{2}$ The melanocortin receptor system (especially melanocortin recep-

Received: January 24, 2017 Revised: May 15, 2017

Accepted: May 24, 2017 Available online: December 1, 2017

$\triangle$ Correspondence: Sermin Algul, $\mathrm{PhD}$

Department of Physiology, Faculty of Medicine, Yuzuncu Yil University, 65100. Tusba, Van, Turkey

Tel: +094322251701, Fax: +904322167519,

E-mail: serminalgul@hotmail.com

(a) This is an Open Access article distributed under the terms of the Creative Commons Attribution Non-Commercial License (http://creativecommons.org/licenses/bync/4.0) which permits unrestricted non-commercial use, distribution, and reproduction in any medium, provided the original work is properly cited. tor 4) has an influence on the regulation of stress-related functions and energy homeostasis. ${ }^{3}$

Noteworthy reports from recent studies revealed endocrine disturbances of some energy regulated hormones in patients with MDD, including nesfatin-1 and ghrelin. ${ }^{4-6}$ Nesfatin-1, which is a satiety molecule in the hypothalamus, has a key regulatory role on body energy metabolic systems via the melanocortin $3 / 4$ receptor without leptin dependent. ${ }^{7-9}$ In addition to its role on food intake and energy regulation, nesfatin-1 has important effects on several neurotransmitter systems and on a number of neural functions. ${ }^{10}$ There are reports of an altered nesfatin- 1 level in various forms of stress-associated psychopathologies in the literature. ${ }^{4,11,12}$

Since 1999, when ghrelin was first defined as the natural endogenous ligand for the growth hormone secretagogue receptor, ${ }^{13}$ it has been found in a variety of other organs. ${ }^{14} \mathrm{~A}$ peripheral orexigenic (appetite-stimulating) hormone, it is involved in the regulation of energy homeostasis, or appetite. ${ }^{15}$ In addition, ghrelin has also been shown to be an important player in 
the regulation of numerous central nervous system functions, including, sleep, cognition, mood and reward. ${ }^{16-19}$ Important$\mathrm{ly}$, the results of some studies showed a close link between ghrelin and depression; ghrelin has been reported as having both an antidepressant and a depressogenic effect in rodents. ${ }^{20,21}$

Although there is some debate on the role of nesfatin- 1 and ghrelin on depression, numerous studies indicate a crucial involvement of nesfatin- 1 and ghrelin in the regulation of the stress response. However, none of the studies found in the literature evaluate the relationship between the severity of MDD and the response of the nesfatin- 1 and the ghrelin hormones. Therefore, understanding the station of these hormones in the psychopathological role in MDD will be an indicator of both the efficiency of the treatment and the prognosis.

We hypothesized that the levels of nesfatin- 1 and ghrelin in patients with major depression would be higher in relationship to the severity of the disease than in healthy subjects. The main point of the present study is in evaluating the possible relationships between nesfatin-1, the ghrelin (acylated and des-acylated) levels and the severity of the MDD.

\section{METHODS}

\section{Participant}

Thirty patients ( 18 female, 12 male) with a moderate degree of MDD and, 30 patients (17 female, 13 male) with a severe degree of MDD were enrolled in the study. In addition 30 subjects ( 15 female, 15 male) without any depression were enrolled as a controls. The age, height, weight and body mass index (BMI) were $37.1 \pm 14 \mathrm{yr}, 167 \pm 5 \mathrm{~cm}, 67.7 \pm 5.1 \mathrm{~kg}$, and $24.3 \pm 3.7 \mathrm{~kg} / \mathrm{m}^{2}$ for the patients with the moderate MDD group, $38.0 \pm 16 \mathrm{yr}, 169 \pm 6 \mathrm{~cm}, 71.4 \pm 5.7 \mathrm{~kg}$, and $25.0 \pm 3.9 \mathrm{~kg} / \mathrm{m}^{2}$ for the severe MDD group and $36.2 \pm 10 \mathrm{yr}, 168 \pm 4 \mathrm{~cm}, 69.7 \pm 7.8$ $\mathrm{kg}$, and $24.7 \pm 1.7 \mathrm{~kg} / \mathrm{m}^{2}$ for the control group, respectively. There were no statistically significant differences in age, height, weight and BMI among the study groups.

The local Ethics Committee approved the study protocol and informed written consent was obtained from each subject. The protocol of this study was conducted in accordance with The Code of Ethics of the World Medical Association (Declaration of Helsinki) for experiments involving humans (The ethic approval number: 11/03/2016; session\#09; Assize:01).

To rule out abnormalities, before the study, each participant underwent a medical screening including medical history, physical examination, hormonal analyses, and cardiovascular risk assessment, which included electrocardiography. It is known that a different co-morbidity, such as a chronic inflammation, and gastrointestinal or nutritional disorders can significantly affect the nesfatin- 1 and ghrelin levels. The exclusion criteria for the patients included the following: physical dis- eases including respiratory, endocrinology, cardiac metabolic or renal diseases, alcohol or drug use disorders, and those receiving any hormonal or drug therapy. Patients aged less than 18 years, those with a BMI of over $30 \mathrm{~kg} / \mathrm{m}^{2}$, who were pregnant, and those with a current diagnosis of malignancy or a psychotic disorder were all excluded.

Based primarily on the 4th edition of the Diagnostic and Statistical Manual of Mental Disorders (DSM-IV), ${ }^{22}$ a depressive episode is defined: A period of two weeks or longer during which there is impaired mood and reduced interest or pleasure in daily activities, pessimism, fatigue, anhedonia, regret, impairment sleep, appetite, failing sexual desire, diminished ability to think and is accompanied by weight change, and reduced physical capacity. Distinct from the definition in the DSMIV, no exclusions were made for a depressive episode caused by medical illness, bereavement, or substance use disorders.

An experienced psychiatrist rated the patients before they entered the study. The classification of the patients with major depressive disorders was made in a clinic using the Hamilton Depression Rating (HAMD) Scale. According to the HAMD scale; $0-7$ is normal, $8-13$ is mild depression, $14-18$ is moderate depression $19-22$ is severe depression, $>23$ is very severe depression. ${ }^{23}$

\section{Hormonal analysis}

The patients were advised not to smoke, drink, eat or exercise in the morning prior to the blood withdrawal. All blood samples were taken between 07:00 and 08:00 in the morning, after an overnight fasting period. Blood samples were centrifuged immediately and plasma was frozen at $-80^{\circ} \mathrm{C}$ until further processing.

The plasma nesfatin-1 measurement was completed using a commercially available enzyme-linked immunosorbent assay (ELISA) kit (Phoenix Pharmaceuticals Inc, Burlingame, CA, USA catalog no: EK-003-26), according to the manufacturer's instructions. The assay had a detection limit of $0.78 \mathrm{ng} / \mathrm{mL}$. The ELISA method was used for the measurement of plasma acylated ghrelin (SPI BIO catalog no: A05106) and des-acylated ghrelin (SPI BIO catalog no: A05119) (SPI BIO, Bertin Pharma Biotech, Montignyle Brettoneux, France). Intra- and interassay coefficients of variation were $8.1 \%$ and $8.3 \%$ for acylated ghrelin and $3.2 \%$ and $3.8 \%$ for desacylated ghrelin, respectively. Care was taken to perform the measurements with kits from the same company. All analyses were performed in a blind fashion in the same experimental set.

\section{Statistical analysis}

Values were expressed as means \pm SD. The KolmogorovSmirnov $\mathrm{Z}$ test showed that the data were normally distributed. Therefore a one way ANOVA test was used to assess be- 
tween-group data comparisons. Comparisons of data regarding subjects of normal and various depression types were assessed using the paired $t$ test. $p<0.05$ was accepted as significant.

\section{RESULTS}

The mean $( \pm S D)$ HAMD score was $3.3 \pm 1.4$ for the control group, $16.1 \pm 1.4$ for the moderate depression group and 20.7 \pm 1.1 for the severe depression group.

The levels of nesfatin-1 (Figure 1), acylated ghrelin (Figure 2) and des-acylated ghrelin (Figure 3 ) in the patients with moderate and severe MDD and the control subjects are shown in the figures. The nesfatin-1 levels of the patients with severe $(3.92 \pm 0.4 \mathrm{ng} / \mathrm{mL}, \mathrm{p}<0.0001)$ and moderate depression $(2.91 \pm$ $0.5 \mathrm{ng} / \mathrm{mL}, \mathrm{p}<0.0001)$ are significantly higher than those of the control group $(1.01 \pm 0.3 \mathrm{ng} / \mathrm{mL}$ ) (Figure 1). The patients with moderate depression have significantly lower nesfatin-1 levels compared to those with severe depression $(\mathrm{p}<0.0001)$ (Figure 1$)$.

The acylated ghrelin levels of the patients with severe de-

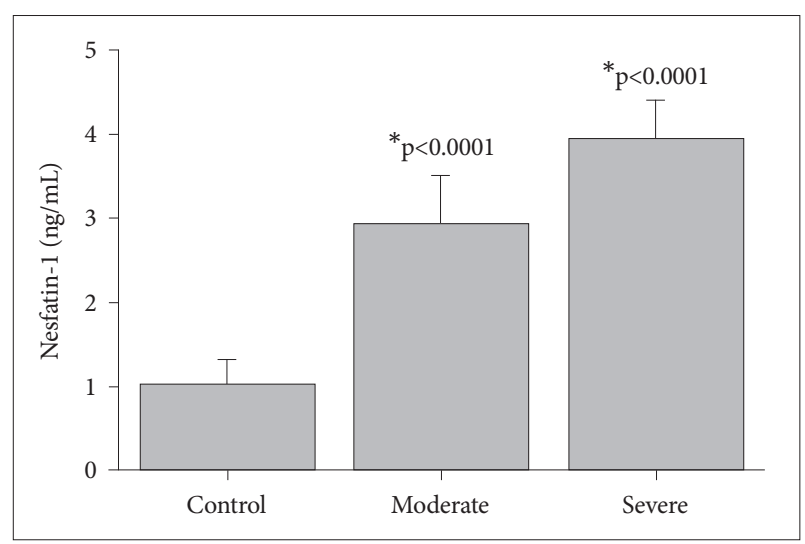

Figure 1. Nesfatin-1 levels response to the control, moderate and severe major depressive groups. Values are presented as mean \pm SD. *significant differences compared to the control levels.

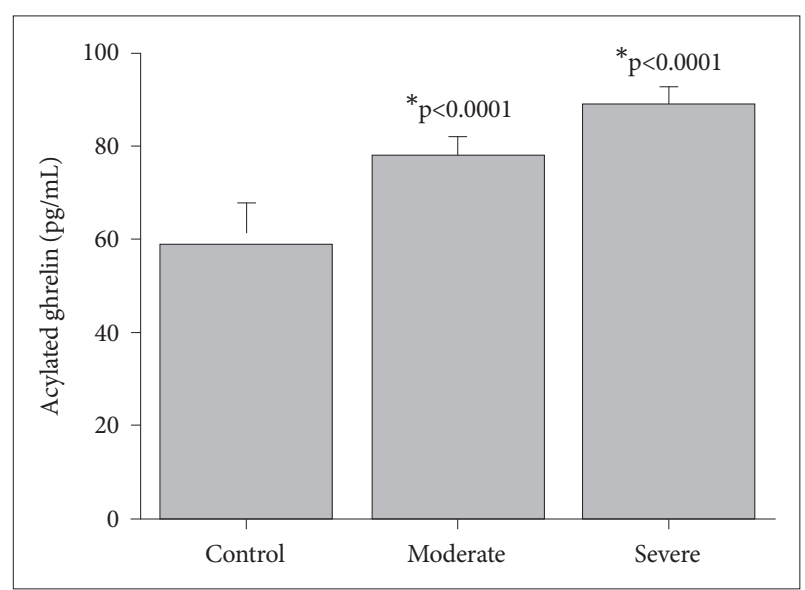

Figure 2. Acylated ghrelin levels response to the control, moderate and severe major depressive groups. Values are presented as mean $\pm S D$. *significant differences compared to the control levels. pression $(88.56 \pm 4.1 \mathrm{pg} / \mathrm{mL})$ are significantly higher than those of control $(58.60 \pm 9.00 \mathrm{pg} / \mathrm{mL}, \mathrm{p}<0.0001)$, and the moderate depression groups $(77.63 \pm 4.19 \mathrm{pg} / \mathrm{mL}, \mathrm{p}<0.0001)$ (Figure 2). The patients with moderate depression have higher acylated ghrelin levels compared to those of the control group $(\mathrm{p}<0.0001)$ (Figure 2).

The des-acylated ghrelin levels of patients with severe depression $(962.76 \pm 67 \mathrm{pg} / \mathrm{mL})$ are significantly higher than those of the control (543.13 $\pm 62 \mathrm{pg} / \mathrm{mL}, \mathrm{p}<0.0001)$, and the moderate depression groups $(631.16 \pm 35 \mathrm{pg} / \mathrm{mL}, \mathrm{p}<0.0001)$ (Figure 3). The patients with moderate depression have higher des-acylated ghrelin levels compared to those of the control group ( $\mathrm{p}<$ 0.0001) (Figure 3).

\section{DISCUSSION}

The main findings of the present study are that the plasma nesfatin-1 and the ghrelin (des-acylated and acylated) levels in severe depressive patients were higher than those in both the moderate depressive patients and the control group. Nesfatin-1 and ghrelin, which are generally known as regulatory hormones of energy homeostasis, ${ }^{7,13}$ may have important therapeutic roles in the endocrine and neuroendocrine regulation of stress related neurodegenerative diseases., ${ }^{4,10,24,25}$

The nesfatin-1 level was found to be significantly higher in moderate depressive patients and it increased further in severe MDD (Figure 1). The distribution of nesfatin-1 in stress sensitive areas in the brain has been shown. ${ }^{10,26}$ The observation of higher nesfatin-1 levels in depressive patients are supports the findings of a previous study that showed stress could increase the plasma nesfatin- 1 levels. ${ }^{27}$

In the present study, we have shown that the severity of depression caused increased ghrelin levels (Figure 2). The satisfactory explanatory data for the relationships between ghre-

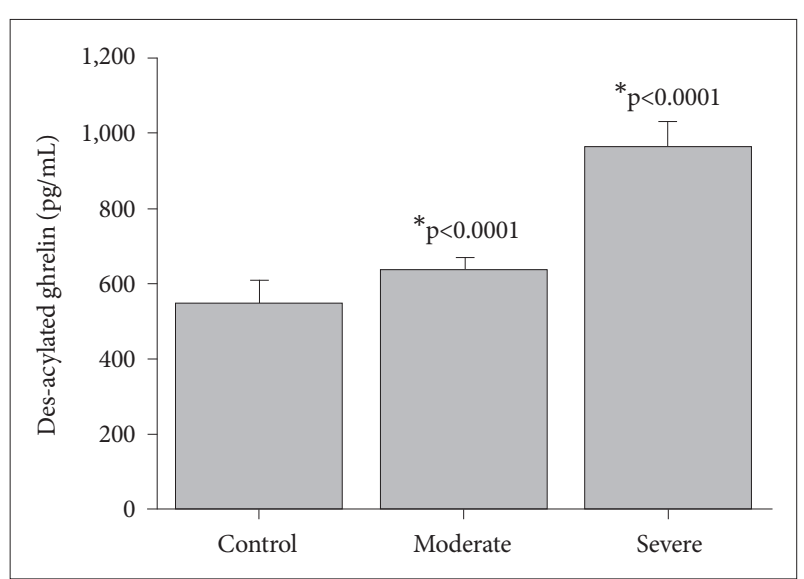

Figure 3. Des-acylated ghrelin levels response to the control, moderate and severe major depressive groups. Values are presented as mean $\pm S D$. *significant differences compared to the control levels. 
lin and depression in humans is limited and it is not consistent. Compared to healthy subjects, the ghrelin plasma or serum levels in patients with MDD were found to be lower, ${ }^{28}$ higher $^{29-31}$ and non-changed. 32,33

There is no clear evidence whether ghrelin contributes to the severity of depression. The studies concerning ghrelin's role in depression showed either an antidepressant ${ }^{21}$ effect or a depressogenic effect. ${ }^{33}$ However, higher plasma acylated ghrelin levels in treatment resistant patients, as compared to control subjects, were reported. ${ }^{6}$ In addition, a significant decrease in the ghrelin levels in depressed patients was reported following antidepressant treatment. ${ }^{31}$ The higher ghrelin level in severe depression could be attributed to effects on neuroprotection. ${ }^{21}$ The neuroprotective effects of ghrelin are shown in neurodegenerative diseases. $^{34}$

Stress induced altered nesfatin- $1^{24}$ and ghrelin ${ }^{35}$ levels have significant effects on neuroendocrinological parameters. Nesfatin-1 and ghrelin are known as adversely affecting hormones on appetite and food intake regulation. ${ }^{36} \mathrm{~A}$ significant reduction in nesfatin-1 levels in patients with diabetes who has serious metabolic impairment, has also been shown. ${ }^{37}$ However, in this study, patients in the severe MDD group had higher nesfatin-1 (Figure 1) and acylated (Figure 2) and des-acylated (Figure 3) ghrelin levels as compared to the moderate MDD and the control group. There is not a clear explanation regarding which molecular mechanism might have the strongest influence on the altered nesfatin-1 and the ghrelin levels in major depressive patients. The significance of the nesfatin- 1 and the ghrelin systems in psychiatric disorders should be clarified to understand their causal involvement in diseases.

The study has limitations that should be taken into consideration. The main limitation is the small sample size of the moderate and severe depression groups. Further studies that focus specifically severity of the depression (including, mild and very severe) with a larger number of patients are needed.

As a conclusion, in clinical medicine, the evaluation of nesfatin- 1 and ghrelin ${ }^{38}$ roles in the endocrine and neuroendocrine regulation of major metabolic functions will be an important key mechanism to solving many diseases associated with endocrine and neuroendocrine disturbances. Increased levels of nesfatin-1 and ghrelin may be important criteria for describing patient prognoses and the effectiveness of treatments.

\section{Acknowledgments}

We gratefully declare that all authors participated with study design, data collection, data analysis, and also manuscript preparation. We would like thank to expert psychiatrist Dr. Bilge KARA (Harput State Hospital, Elazig) for her technical assistance in depressive patients classification.

\section{REFERENCES}

1. Mischoulon D, Eddy KT, Keshaviah A, Dinescu D, Ross SL, Kass AE, et al. Depression and eating disorders: treatment and course. J Affect Disord 2010;130:470-477.

2. de Kloet ER, Joels M, Holsboer F. Stress and the brain: from adaptation to disease. Nat Rev Neurosci 2005;6:463-475.

3. Serova LI, Laukova M, Alaluf LG, Sabban EL. Blockage of melanocortin-4 receptors by intranasal HS014 attenuates single prolonged stresstriggered changes in several brain regions. J Neurochem 2014;131:825835.

4. Ari M, Ozturk OH, Bez Y, Oktar S, Erduran D. High plasma nesfatin-1 level in patients with major depressive disorder. Prog Neuropsychopharmacol Biol Psychiatry 2011;35:497-500.

5. Bloem B, Xu L, Morava E, Faludi G, Palkovits M, Roubos EW, et al. Sex-specific differences in the dynamics of cocaine- and amphetamineregulated transcript andnesfatin-1 expressions in the midbrain of depressed suicide victims vs. controls. Neuropharmacology 2012;62:297303.

6. Ishitobi Y, Kohno K, Kanehisa M, Inoue A, Imanaga J, Maruyama Y, et al. Serum ghrelin levels and the effects of antidepressants in major depressive disorder and panic disorder. Neuropsychobiology 2012;66: 185-192.

7. Oh-I S, Shimizu H, Satoh T, Okada S, Adachi S, Inoue K, et al. Identification of nesfatin-1 as a satiety molecule in the hypothalamus. Nature 2006;443:709-712.

8. Yosten GL, Samson WK. Nesfatin-1 exerts cardiovascular actions in brain: possible interaction with the central melanocortin system. Am J Physiol Regul Integr Comp Physiol 2009;297:330-336.

9. Nonogaki K, Ohba Y, Sumii M, Oka Y. Serotonin systems upregulate the expression of hypothalamic NUCB2 via 5- HT2C receptors and induce anorexia via a leptin independent pathway in mice. Biochem Biophys Res Commun 2008;372:186-190.

10. Yoshida N, Maejima Y, Sedbazar U, Ando A, Kurita H, Damdindorj B, et al. Stressor-responsive central nesfatin-1 activates corticotropin-releasing hormone, noradrenaline and serotonin neurons and evokes hypothalamic-pituitary-adrenal axis. Aging (Albany NY) 2010;2:775-784.

11. Pałasz A, Krzystanek M, Worthington J, Czajkowska B, Kostro K, Wiaderkiewicz R, et al. Nesfatin-1, a unique regulatory neuropeptide of the brain. Neuropeptides 2012;46:105-112.

12. Hofmann T, Ahnis A, Elbelt U, Rose M, Klapp BF, Stengel A. NUCB2/ nesfatin-1 is associated with elevated levels of anxiety in anorexia nervosa. PLoS One 2015;10:e0132058.

13. Kojima M, Hosoda H, Date Y, Nakazato M, Matsuo H, Kangawa K. Ghrelin is a growth-hormone-releasing acylated peptide from stomach. Nature 1999;402:656-660.

14. Gnanapavan S, Kola B, Bustin SA, Morris DG, McGee P, Fairclough P, et al. The tissue distribution of the mRNA of ghrelin and subtypes of its receptor, GHS-R, in humans. J Clin Endocrinol Metab 2002;87:2988.

15. Nakazato M, Murakami N, Date Y, Kojima M, Matsuo H, Kangawa K, et al. A role for ghrelin in the central regulation of feeding. Nature 2001; 409:194-198.

16. Chuang JC, Zigman JM. Ghrelin's roles in stress, mood, and anxiety regulation. Int J Pept 2010;2010:460549.

17. Jerlhag E, Egecioglu E, Landgren S, Salomé N, Heilig M, Moechars D, et al. Requirement of central ghrelin signaling for alcohol reward. Proc Natl Acad Sci USA 2009;106:11318-11323.

18. Andrews ZB. The extra-hypothalamic actions of ghrelin on neuronal function. Trends Neurosci 2011;34:31-40.

19. Spencer SJ, Emmerzaal TL, Kozicz T, Andrews ZB. Ghrelin's role in the hypothalamic-pituitary-adrenal axis stress response: implications for mood disorders. Biol Psychiatry 2015;78:19-27.

20. Kanehisa M, Akiyoshi J, Kitaichi T, Matsushita H, Tanaka E, Kodama K, et al. Administration of antisense DNA for ghrelin causes an antidepressant and anxiolytic response in rats. Prog Neuropsychopharmacol Biol Psychiatry 2006;30:1403-1407.

21. Lutter M, Sakata I, Osborne-Lawrence S, Rovinsky SA, Anderson JG, Jung $\mathrm{S}$, et al. The orexigenic hormone ghrelin defends against depressive 
symptoms of chronic stress. Nat Neurosci 2008;11:752-753.

22. American Psychiatric Association. Diagnostic and Statistical Manual of Mental Disorders. 4th Edition. Washington DC: American Psychiatric Press; 1994.

23. Hamilton M. A rating scale for depression. J Neurol Neurosurg Psychiatry 1960;23:56-62.

24. Emmerzaal TL, Kozicz T. Nesfatin-1; implication in stress and stressassociated anxiety and depression. Curr Pharm Des 2013;19:6941-6948.

25. Labarthe A, Fiquet $\mathrm{O}$, Hassouna R, Zizzari P, Lanfumey L, Ramoz N, et al. Ghrelin-Derived Peptides: A Link between Appetite/Reward, GH Axis, and Psychiatric Disorders? Front Endocrinol (Lausanne) 2014;5:163.

26. Brailoiu GC, Dun SL, Brailoiu E, Inan S, Yang J, Chang JK, et al. Nesfatin-1: distribution and interaction with a $\mathrm{G}$ protein-coupled receptor in the rat brain. Endocrinology 2007;148:5088-5094.

27. Xu YY, Ge JF, Qin G, Peng YN, Zhang CF, Liu XR, et al. Acute, but not chronic, stress increased the plasma concentration and hypothalamic mRNA expression of NUCB2/nesfatin-1 in rats. Neuropeptides 2015; 54:47-53.

28. Barim AO, Aydin S, Colak R, Dag E, Deniz O, Sahin I. Ghrelin, paraoxonase and arylesterase levels in depressive patients before and after citalopram treatment. Clin Biochem 2009;42:1076-1081.

29. Schmid DA, Wichniak A, Uhr M, Ising M, Brunner H, Held K, et al. Changes of sleep architecture, spectral composition of sleep EEG, the nocturnal secretion of cortisol, ACTH, GH, prolactin, melatonin, ghrelin, and leptin, and the DEX-CRH test in depressed patients during treatment with mirtazapine. Neuropsychopharmacology 2006;31:832-
844.

30. Kurt E, Guler O, Serteser M, Cansel N, Ozbulut O, Altinbaş K, et al. The effects of electroconvulsive therapy on ghrelin, leptin and cholesterol levels in patients with mood disorders. Neurosci Lett 2007;426:49-53.

31. Ozsoy S, Besirli A, Abdulrezzak U, Basturk M. Serum ghrelin and leptin levels in patients with depression and the effects of treatment. Psychiatry Investig 2014;11:167-172.

32. Kluge M, Schüssler P, Schmid D, Uhr M, Kleyer S, Yassouridis A, et al. Ghrelin plasma levels are not altered in major depression. Neuropsychobiology 2009;59:199-204.

33. Hansson C, Haage D, Taube M, Egecioglu E, Salomé N, Dickson SL. Central administration of ghrelin alters emotional responses in rats: behavioral, electrophysiological and molecular evidence. Neuroscience 2011;180:201-211.

34. Bayliss JA, Andrews ZB. Ghrelin is neuroprotective in Parkinson's disease: molecular mechanisms of metabolic neuroprotection. Ther Adv Endocrinol Metab 2013;4:25-36.

35. Bali A, Jaggi AS. An integrative review on role and mechanisms of ghrelin in stress, anxiety and depression. Curr Drug Targets 2016;17:495-507.

36. Stengel A, Goebel M, Wang L, Taché Y. Ghrelin, des-acyl ghrelin and nesfatin-1 in gastric X/A-like cells: role as regulators of food intake and body weight. Peptides 2010;31:357-369.

37. Algul S, Ozkan Y, Ozcelik O. Serum nesfatin-1 levels in patients with different glucose tolerance levels. Physiol Res 2016;65: 979-985.

38. Wittekind DA, Kluge M. Ghrelin in psychiatric disorders a review. Psychoneuroendocrinology 2015;52:176-194. 